\title{
Roger W. Byard: Sudden death in the young
}

\author{
Cambridge University Press, 2010, 685 pp, ISBN 978-0-521-51661-7
}

\author{
Michael Tsokos
}

Accepted: 8 February 2011/Published online: 23 February 2011

(C) Springer Science+Business Media, LLC 2011

Investigating the death of infants, children and/or adolescents and determining the precise cause and manner of death in the young are not easy tasks and constitute continuing challenges in forensic autopsy practice. The author of this book, Professor Roger Byard, is both Professor of Pathology at The University of Adelaide and a Senior Forensic Pathologist at Forensic Science SA, and with his two positions he has an extensive and longstanding experience with the deaths of infants, children and young adults in a forensic context. There is a critical need for such a comprehensive pediatric pathology book since many pathological conditions are quite rare, which means that most pathologists, even after many years of experience in both the autopsy and court room, may not be familiar with specific entities.

Undoubtedly, the majority of the readers of this journal are well aware of Byard's two previous editions of this book (formerly entitled Sudden Death in Infancy, Childhood and Adolescence). However, this 3rd edition represents a completely revised version of the 2 nd edition. Not only the title has changed, but the text has been significantly expanded and the format of the book has been enlarged. However, the most impressive modification of this 3rd edition is the laudable feature that now nearly all figures are printed in color and over 350 new high quality photographs of autopsy and histological findings have been added.
This work is much more than just another textbook on pediatric pathology. This is also a reference pediatric pathology atlas of outstanding quality with over 800 color photographs, as well as a source for scrutinizing even rare histological diagnoses in a case-by-case approach. The author also provides an extensive bibliography with many hundreds of new, up-to-date references.

Sudden Death in the Young consists of six sections (Section 1: Introduction, Section 2: Unintentional trauma, Section 3: Intentional trauma, Section 4: Natural disease, Section 5: Maternal, fetal, and neonatal conditions, Section 6: Sudden infant death syndrome), comprising 14 chapters, that are arranged in a logical order and cover the broad spectrum of natural and non-natural causes of death that the pathologist may encounter. Section 5 (Maternal, fetal, and neonatal conditions) is completely new and not a part of previous editions of this book. The 14 chapters are followed by numerous forms, templates, tables and figures with growth charts and organ weights as well as autopsy checklists for non-accidental injury and metabolic disorders. At the end of the book, a comprehensive, 13 pages index is exhaustive in its scholary breadth.

This is a book that anyone involved in the investigation of death will find fascinating and most helpful.

M. Tsokos $(\square)$

Institute of Legal Medicine and Forensic Sciences, Charité, Universitätsmedizin Berlin, Turmstr. 21 (Haus L), 10559 Berlin, Germany

e-mail: mtsokos@web.de 